\title{
Reducing skin tears, workload, and costs in the frail aged: Replacing showers with bath cloths
}

\author{
Catherine Anne Sharp ${ }^{1}$, Julie Campbell ${ }^{2}$ \\ ${ }^{1}$ Practicing Nurse, ${ }^{2}$ Practicing Nurse, Palliative Care Nursing, The Wound Centre, Sydney, Australia
}

Background: Two Nurse Consultants, as part of their usual practice of auditing wounds in a 25-bed dementia unit of an aged care facility in Sydney, Australia, reported on skin tears (STs), wounds that occur mainly on the forearms of the elderly and often during showering. Aims and Objectives: The main aims were to measure and reduce the prevalence of STs; replace showers with HiCare ${ }^{\mathrm{TM}}$ bath cloths; reduce the nurses' workload; reduce costs for laundry and wound dressings and a new regime for showering residents introduced. Materials and Methods: Bedside training was given to care staff, and data on time taken to bed-bath, HiCare ${ }^{\mathrm{TM}}$ bath and shower, were collected, collated and costs estimated. Results: Three of 25 residents $(12 \%)$ had a total of six STs. Following the introduction of the HiCare ${ }^{\mathrm{TM}}$ bath system the incidence of STs decreased by $96 \%$ in 6 weeks and cost savings were \$AUD 6.76/resident. Conclusion: The number of showers performed each day by nurses was reduced allowing nurses more time to feed residents, go for a walk and sit in the garden. These practice changes benefit the residents as well as the nurses.

Key words: Bath cloths; Cost-savings; Showering; Skin tears

\section{Access this article online}

\section{Website:}

http://nepjol.info/index.php/AJMS DOI: 10.3126/ajms.v13i2.40548

E-ISSN: 2091-0576

P-ISSN: $2467-9100$

Copyright (c) 2022 Asian Journal of Medical Sciences

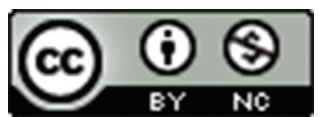

This work is licensed under a Creative Commons Attribution-NonCommercial 4.0 International License.

\section{INTRODUCTION}

"A skin tear (ST) is a wound caused by shear, friction and/or blunt force resulting in the separation of skin layers. A ST can be partial thickness (separation of the epidermis from the dermis) or full thickness (separation of both the epidermis and the dermis from the underlying structures)."

STs are common in the elderly in residential aged care facilities (RACFs). ${ }^{1-4}$ They may be viewed as a quality of care issue, ${ }^{1}$ because they are often a source of great discomfort, exacerbated during wound dressing changes particularly when dressings stick, causing pain and further trauma on removal. Each ST increases workload and costs. ${ }^{2}$

STs occur during manual handling episodes such as bed-bathing and showering frail aged, residents with limited, or no, mobility. These tasks are time-consuming and can be physically tiring for nurses and frightening for residents who may react with resistive behavior. Resistive behavior may result in both the resident and the nurse getting hurt. The resident may sustain STs further increasing the likelihood of resistive behavior. The contributing factors include pain, fatigue, confusion, anxiety being naked in front of strangers, a fear of falling and cold showers. ${ }^{5}$

This short report describes interventions to prevent STs in a 25-bed high care dementia unit where all 25 residents were deemed at risk of STs from manual handling during showering, dressing, bathing, repositioning and transferring. More than $50 \%$ of residents were completely immobile and dependent on nurses for all activities of daily living (ADL). The remainder required at least one nurse to ambulate and assist with all ADLs.

At the beginning of the study period three of 25 residents $(12 \%)$ had a total of six STs. One of these 
residents, who were immobile, required 2:1 assistance. The other two residents required 1:1 to mobilise. One regularly screamed and fought in the shower, where she developed STs.

\section{Occupational health and safety}

Observing the nurses at work raised some major concerns. In the 25-bed high care facility, many nurses were working alone putting residents into lifters to push them to the shower. They were bed-bathing and showering alone, potentially dangerous practices. The nurses were showering as many as eight residents each, working alone. This takes time and is a concern as far as manual handling issues.

\section{Aims and objectives}

The main aims were to measure and reduce the prevalence of skin tears; replace showers with $\mathrm{HiCare}^{\mathrm{TM}}$ bath cloths; reduce the nurses' workload; reduce costs for laundry and wound dressings and a new regime for showering residents introduced.

\section{MATERIALS AND METHODS}

The usual practice of showering all residents every day was replaced with HiCare ${ }^{\mathrm{TM}}$ bath cloths, a non-alcoholic bath cloth versus soap and water, provided by Human Technologies ${ }^{\circledR}$ for the 25-bed high care ward of RACF and a new regime for showering residents was introduced. This study was part of daily care and as such Ethics approval was not required. One-on-one bedside training of care staff was given. Data on time taken to carry out a traditional bed-bath, HiCare ${ }^{\mathrm{TM}}$ bath and shower, were collected and cost savings estimated (Table 1).

\section{RESULTS}

Time taken for two nurses to shower one immobile resident using a mechanical lifter was as much as $40 \mathrm{~min}$. Using the HiCare $^{\mathrm{TM}}$ bath cloths the fastest bed-bath with two nurses took only $2 \mathrm{~min}$. No new STs occurred during a six-week period (Table 1).

\section{DISCUSSION}

In this study the prevalence of STs decreased by $96 \%$, there were no new STs in the six weeks following the introduction of the HiCare ${ }^{\mathrm{TM}}$ bath system. The results are similar to those observed by others ${ }^{6}$ who found a $90 \%$ reduction in the total number of STs over 12 weeks when the change was made from using soap and water to a no-rinse formula for bathing.

The workload for nurses was reduced and no manual handling injuries occurred whilst bathing residents with $\mathrm{HiCare}^{\mathrm{TM}}$. Bed-bathing residents quickly results in a clean bowl of water becoming a "bacteria soup." Before introducing the HiCare ${ }^{\mathrm{TM}}$ bath cloth it was not uncommon to hear residents' shouting from the shower and occasionally see them lashing out at nurses. This behavior, which may indicate terror or pain, disappeared when showering was replaced with gentle, warm, HiCare ${ }^{\mathrm{TM}}$ bath cloths.

Towels are not required when $\mathrm{HiCare}{ }^{\mathrm{TM}}$ bath cloths are used. In this high-care facility extrapolated, over 52 weeks the number of towels will be reduced to approximately one third (3068 towels). In addition, by reducing the number of towels used the number of linen skips that need to be dragged along the floor to a linen chute (usually by a nurse) is also reduced. This reduces the risk of manual handling injuries too.

\section{Laundry costs}

In this 25-bed unit, if only one towel per resident is used it is estimated that a minimum of 9,100 towels would be used and require laundering annually when all residents are showered, or bed-bathed in the traditional manner. However, what often happens is that two towels are used; one is dropped on the floor for the resident to stand on

\begin{tabular}{|c|c|c|c|c|c|}
\hline \multirow[t]{2}{*}{ DAY } & \multicolumn{3}{|c|}{ Number of Residents } & \multirow{2}{*}{$\begin{array}{c}\text { Showers } \\
\text { Total }\end{array}$} & \multirow{2}{*}{$\begin{array}{c}\text { HiCare }^{\mathrm{TM}} \\
\text { Total }\end{array}$} \\
\hline & 8 & 8 & 9 & & \\
\hline Mon & Hi Care & Hi Care & Shower & 9 & 16 \\
\hline Tue & Shower & Hi Care & Hi Care & 8 & 17 \\
\hline Wed & Hi Care & Shower & Hi Care & 8 & 17 \\
\hline Thur & Hi Care & Hi Care & Shower & 9 & 16 \\
\hline Sat & Hi Care & Shower & Hi Care & 8 & 17 \\
\hline Sun & Hi Care & Hi Care & Shower & 9 & 16 \\
\hline TOT & & & & 59 showers $=59$ towels (minimum) & 116 HiCare $^{\mathrm{TM}}$ Bath cloths $=0$ towels \\
\hline
\end{tabular}


to prevent slipping. The cost at the time of laundering one towel quoted at a major hospital in Sydney is $\$ 4.17$ (pers. comm. Wound Care Clinical Nurse Consultant). Therefore, the cost of two towels per resident per bedbath/shower is $\$ 8.35$. Towels are not required when HiCare $^{\mathrm{TM}}$ bath cloths are used. The difference between using HiCare ${ }^{\mathrm{TM}}$ bath cloths and towels was $\$ 6.76 /$ resident.

The staff of this 25-bed high care dementia unit said they were extremely happy with the HiCare ${ }^{\mathrm{TM}}$ bath cloth regime. The change to HiCare ${ }^{\mathrm{TM}}$ resulted in a reduction in the number of residents being showered each day, thus reducing the potential for nurses to injure their backs. The change in nursing practice appeared to have played a role in reducing the incidence of STs over 6 weeks consequently the financial outlay for wound care and ST dressings was reduced. In countries like Australia, where saving water is very much at the forefront of political agendas $\mathrm{HiCare}^{\mathrm{TM}}$ bath cloths make for a perfect intervention.

There are, of course, residents who want to be showered every day and this will be made easier for staff when they have fewer showers to do each day.

\section{Advantages of HiCare ${ }^{\text {TM }}$ bath cloths}

There are many advantages when using HiCare ${ }^{\text {TM }}$ bath cloths:

No bowls of water to carry therefore less likelihood of back injuries from weight of water or slipping on wet floors.

No washing residents with a "bacteria soup mix in a bowl" therefore less likelihood of Spreading infection.

No bowls to scrub.

No water required.

No towels to launder.

Sheets don't get wet therefore fewer sheets to launder.

Reduces risk of manual handling injuries to residents.

Reduces risk of staff being injured when working with resistive residents.

\section{Limitations of the study}

This study was based mainly on one subjective observation: the development of new STs. Whether certain residents were more prone to STs than others was not taken into consideration although one resident with a history of repeated STs was often reluctant to be showered and expressed this with some resistant behavior. However, the fact that no new STs occurred during a six-week period using HiCare ${ }^{\mathrm{TM}}$ bath cloths provided raw data for the authors to determine that the new cleansing regimen using HiCare $^{\mathrm{TM}}$ bath cloth may have had a positive impact.

\section{CONCLUSION}

By changing work practices to incorporate a $\mathrm{HiCare}^{\mathrm{TM}}$ bath cloth regime the number of showers performed each day by nurses was reduced from around eight per nurse to no more than three. This allowed nurses more time to provide essential nutrition and hydration, take residents for a walk and sit with them in the garden. The restructuring of care was embraced by nurses. Although not measured, comments from nurses and the authors' observations, made it clear that these practice changes not only benefit the residents but nurses as well.

\section{DISCLAIMER}

Neither author has ever been paid by any company to promote HiCare, ${ }^{\mathrm{TM}}$ or any other, bath cloths.

\section{ACKNOWLEDGMENT}

We thank Human Technologies ${ }^{\circledR}$ for donating HiCare ${ }^{\mathrm{TM}}$ bath cloths for the purpose of this "trial." We especially thank all the nurses without whose enthusiasm this "trial" would not have succeeded.

\section{REFERENCES}

1. LeBlanc K, Baranoski S and Holloway S. A descriptive crosssectional international study to explore current practices in the assessment, prevention and treatment of skin tears. Int Wound J. 2014;11(4):424-430.

https://doi.org/10.1111/iwj.12203

2. Lewin GF, Newall $\mathrm{N}$ and Alan JJ. Identification of risk factors associated with the development of skin tears in hospitalised older persons: A case-control study. Int Wound J. 2016;13(6):1246-1251.

https://doi:10.1111/iwj.12490

3. Cowdell F, Jadotte YT and Ersser SJ. Hygiene and emollient interventions for maintaining skin integrity in older people in hospital and residential care settings. Cochrane Database Syst Rev. 2020;1(1):Cd011377.

https://doi:10.1002/14651858.CD011377.pub2

4. Carville K, Leslie $\mathrm{G}$ and Osseiran-Moisson R. The effectiveness of a twice-daily skin-moisturising regimen for reducing the incidence of skin tears. Int Wound J. 2014;11(4):446-453.

https://doi.org/10.1111/iwj.12326

5. Rader JB, Barrick AL and Hoeffer B. The bathing of older adults with dementia. Easing the unnecessarily unpleasant aspects of assisted bathing. Am J Nurs. 2006;106(4):40-48. 
https://doi.org/10.1097/00000446-200604000-00026

6. Plante $L$ and Regan $M$. Impact of one-step, no-rinse bathing on cost of care and skin tear occurrence in the long-term care setting. Poster session presented at the annual meeting of the association for advancement of wound care. Wound Manag Prev. 1996.
7. Martin ET, Haider S and Palleschi M. Bathing hospitalized dependent patients with prepackaged disposable washcloths instead of traditional bath basins: A case-crossover study. Am J Infect Control. 2017;45(9):990-994.

https://doi.org/10.1016/j.ajic.2017.03.023

Authors Contribution:

CAS, JC-Contributed equally to the concept and design of the study, literature reviews and preparation of manuscript.

\section{Work attributed to:}

The Wound Centre, Sydney, Australia

\section{Orcid ID:}

Ms. Catherine Anne Sharp - (1) https://orcid.org/0000-0002-4266-8493

Ms. Julie Campbell - (D) https://orcid.org/0000-0002-2140-0017

Source of Support: Nil, Conflict of Interest: None. 